\title{
Phospholipid bilayers as vehicles of anthraquinone disperse dyes in wool dyeing
}

\author{
A de la Maza and J L Parra
}

\author{
Departamento de Tensioactivos, Centro de Investigación y Desarrollo CSIC, Calle Jorge Girona, 18-26, \\ 08034 Barcelona, Spain
}

\begin{abstract}
The use of multilamellar lipid vesicles as carriers of disperse dyes on wool fibres has been studied. Liposomes made from egg phosphatidylcholine containing the anthraquinone dye CI Disperse Violet 1 at different phospholipid/dye concentrations were used. The physical stability of these systems was assessed by measuring the mean vesicle size distribution of lipid vesicle suspensions after preparation and during dyeing. Kinetic aspects involving dye adsorption and bonding on untreated and chlorinated wool samples by means of the liposomes at different dye/lipid ratios were also investigated. This process led to the controlled dye exhaustion on wool, directly dependent on the relationship between the dye and lipid components, with a clear improvement in the dye-fibre bonding forces and in the dispersing efficiency, compared with conventional dispersing agents. The optimum dye exhaustion was reached for the dye/phospholipid concentrations 0.53 and $1.0 \mathrm{mmol} / \mathrm{l}$ respectively. The maximum amounts of dye bonded on untreated wool fibre were obtained for the same dye/lipid molar ratio. However, chlorinated wool samples showed a slight decrease in the total bonded dye as the chlorination level increased.
\end{abstract}

\section{INTRODUCTION}

Phospholipid vesicles or liposomes are interesting structures that have come into widespread use as models for biological membranes and as delivery systems where encapsulation and protection of hydrophilic and lipophilic substances are required [1-6]. Although initially slow to exploit liposome technology, the textile industry has now produced a wide variety of innovations using the basic principles of targeting, slow release and protection of sensitive chemicals, principally in dyeing and finishing $[7,8]$.

One area of potential application of liposomes is in the dyeing of wool and its blends (particularly wool/polyester) with disperse dyes. Although disperse dyes have good affinity for protein fibres, they have not been used hitherto for wool [9]. Irregular staining and, in some cases, poor wash fastness are the main disadvantages of these dyes for wool dyeing. The correct choice of disperse dye and dyeing conditions, and the use of a suitable carrier are all very important factors in preventing irregular staining, which is particularly pronounced when dyeing wool/ polyester blends [10].

Barni reported the use of 'double-tailed' surfactants suitable for the preparation of synthetic vesicles in the dyeing polyester with disperse dyes, resulting in good levelling and in a faster rate of dye migration [11]. Likewise, liposomes have been investigated as vehicles of the oxidative reagent in wool chlorination [12].

We previously described the use of large unilamellar phosphatidylcholine liposomes as carriers in commercial dyeing of untreated wool using a milling acid dye [7]. The aim of the present work was to investigate the possibilities of using liposomes as carriers of anthraquinone disperse dyes to improve the dye exhaustion and dye-fibre bonding on wool without resorting to dispersing agents. In this connection, we describe work on the physical stability of multilamellar vesicle (MLV) liposomes containing an anthraquinone disperse dye at different dye/phospholipid molar ratios. The application of these structures in dyeing of untreated and chlorinated wool fibres has also been examined, focusing on the kinetic aspects of dye adsorption and the dye-fibre bonding forces on wool fibres.

\section{EXPERIMENTAL}

\section{Materials}

Botany wool fabrics knitted from R64/2 tex (count $2 / 28$ ) yarns were used. Samples were Soxhlet extracted for $2 \mathrm{~h}$ with methylene chloride and rinsed with water purified by the Milli-Ro (Millipore) system and dried at room temperature.

The disperse dye Oracetblau 2R (Merck, CI Disperse Violet 1) was used; its structure is given in Figure 1. This dye was selected as being a typical anthraquinone disperse dye, sparingly soluble in water $\left(0.3 \mathrm{mg} / \mathrm{l}\right.$ at $\left.25^{\circ} \mathrm{C}\right)$ and needing a high concentration of surface-active agent to be dispersed $(17 \mathrm{mg} / \mathrm{l}$ in $1 \%$ sodium oleyl-p-anisidide sulphonate solution (Lissapol LS)) [13].

Phosphatidylcholine (PC) was purified from egg lecithin (Merck) according to the method of Singleton [14], and shown to be pure by thin layer chromatography. Polycarbonate membranes of 400 and $800 \mathrm{~nm}$, and membrane holders used for liposome extrusion were purchased from Nucleopore (Pleasanton, CA). 
<smiles>Nc1ccc(N)c2c1C(=O)c1ccccc1C2=O</smiles>

Figure 1 Chemical structure of $\mathrm{Cl}$ Disperse Violet 1 (Oracetblau 2R)

The nonionic surfactant Triton X-100 (octylphenol with ten units of ethylene oxide) was specially prepared by Tenneco España SA. The sodium hypochlorite solution was an $80 \mathrm{~g} / \mathrm{l}$ active chlorine solution obtained from Carlo Erba. The other chemicals used throughout were of laboratory-reagent quality.

\section{Preparation of MLV liposomes}

MLVs of a defined vesicle size (400 nm), at different dye and phospholipid concentrations $(0.25-1.0 \mathrm{mmol} / \mathrm{l}$ and $0.50-2.50 \mathrm{mmol} / /$ respectively), were prepared following a method described by Bangham [15]. A film was formed by removing the organic solvent from a chloroform/methanol 2:1 solution of egg phosphatidylcholine/dye by rotary evaporation in a nitrogen atmosphere and low vacuum $47 \mathrm{kPa}(350 \mathrm{~mm} \mathrm{Hg})$. An aqueous phase containing 5\% sodium sulphate and acetic acid (pH 5.5) was added to the lipid film. The solutions were then swirled by hand to remove the lipid from the walls of the flask and to disperse large lipid/dye aggregates; glass beads were added to facilitate dispersion. The resulting milky suspensions were vortexed for $5 \mathrm{~min}$ and sonicated for $15 \mathrm{~min}$ at $30^{\circ} \mathrm{C}$ and $75 \mathrm{~W}$ (Labsonic $1510 \mathrm{~B}$, Braun). Liposome suspensions were extruded through 400 and $800 \mathrm{~nm}$ polycarbonate membranes to obtain a uniform size distribution [16]. After preparation the resulting liposome suspensions were left to equilibrate for $15 \mathrm{~min}$ and immediately applied in wool dyeing processes.

\section{Dyeing procedure}

Knitted wool samples were treated with MLV liposome suspensions freshly prepared at different dye/ phospholipid molar ratios in the phospholipid concentration range $0.5-2.5 \mathrm{mmol} / \mathrm{l}$. The dye was applied at $0.5-2.0 \%$ o.w.f., which corresponded to a dye concentration range of $0.26-1.0 \mathrm{mmol} / \mathrm{h}$, with $5 \%$ o.w.f. anhydrous sodium sulphate, acetic acid at $\mathrm{pH} 5.5$ and at a liquor ratio of 60:1.

Dyeing was started at $50^{\circ} \mathrm{C}$ and the temperature was raised by $0.9 \mathrm{degC} / \mathrm{min}$ to $90^{\circ} \mathrm{C}$. Dyeing was continued for $120 \mathrm{~min}$. Thereafter samples were rinsed with water for 10 $\mathrm{min}$ and dried at room temperature. Laboratory dyeing was carried out in a Multi-Mat dyeing machine (Renigal).

Dyebath exhaustion was determined by spectrophotometry using a Shimadzu UV-265FW spectrophotometer. Liposome aliquots $(0.5 \mathrm{ml})$ were periodically added to quartz cuvettes filled with $2 \mathrm{ml}$ aqueous solution of Triton X-100 $(20 \mathrm{~g} / \mathrm{l})$, supplemented with sodium sulphate $(5 \%)$. The interaction between the nonionic surfactant Triton X-100 and liposome structures resulted in solubilisation of phospholipid vesicles via mixed micelle formation [17,18], turning the liposome suspension into a clear solution.

The effect of the cleavage of liposome vesicles by Triton X-100 on the absorption spectra of the CI Disperse Violet 1 in the lipid concentration range studied did not change the $\lambda_{\max }$ value of the dye in the presence of these phospholipid/surfactant structures.

\section{Determination of encapsulation efficiency and mean size distribution of liposome vesicles}

The maximum amounts of dye dispersed with the MLV liposomes is defined as the weight ratio between the dispersed dye and the phospholipid in liposomes, $K$, and was determined spectrophotometrically. After preparation, liposome suspensions were left to equilibrate for $12 \mathrm{~h}$. Afterwards vesicle suspensions were spun at 5000 $\mathrm{rev} / \mathrm{min}$ for $15 \mathrm{~min}$ at $25^{\circ} \mathrm{C}$ in order to remove the unencapsulated dye. Finally the concentration of dispersed dye was evaluated by spectrophotometry after the destruction of the supernatant lipid bilayers by addition of Triton X-100 [17,18].

Mean vesicle size and polydispersity of the liposome preparations were determined by a Photon correlator spectrometer (Malvern Autosizer 4700c PS/MV). Particle size distribution was studied by particle number measurements. Samples were adjusted to the appropriate concentration range. The measurements were made at $20^{\circ} \mathrm{C}$ with a detection angle of $90^{\circ}$.

\section{Aggregation measurements}

The aggregation state of the vesicles was estimated as a measure of the physical stability of the liposome suspensions. This was done by monitoring the variation of the mean vesicle size distribution of liposome suspensions as a function of time.

\section{Phosphorus estimation of liposomes}

The phospholipid concentration of liposomes was determined by the ascorbic acid spectrophotometric method for total phosphorus estimation [19].

\section{Dye extraction}

The dye bonded superficially to the fibres by non-polar forces (hydrophobic interactions, van der Waals forces and hydrogen bonds) was extracted with pure ethanol for 60 $\min$ at $25^{\circ} \mathrm{C}$ [7]. Subsequent extractions with ammonia solution $\left(0.5 \%\right.$ for $15 \mathrm{~min}$ at $\left.60^{\circ} \mathrm{C}\right)$ stripped the dye diffused inside the fibre and bonded ionically [13].

\section{Wool fibre chlorination}

Wool samples $(1 \mathrm{~g})$ were treated with different concentrations of sodium hypochlorite solutions $(0.35-2.8$ $\mathrm{g} /$ ( chlorine), after adjusting the $\mathrm{pH}$ of solutions to 1.5 with hydrochloric acid $(\mathrm{KCl} / \mathrm{HCl}$ buffer). The treatments were carried out for $15 \mathrm{~min}$ at $25^{\circ} \mathrm{C}$ with constant stirring in a closed bath. After the treatments the samples were rinsed 
with water and treated with sodium metabisulphite $(1 \%)$ at a liquor ratio of $30: 1$ for $5 \mathrm{~min}$ to remove the excess oxidising agent. The chlorinated wool samples were then rinsed in water purified by the Milli-Ro system and dried at room temperature. The concentration of active chlorine in the sodium hypochlorite solutions was determined using the iodometric method [20].

\section{RESULTS AND DISCUSSION}

\section{Encapsulation efficiency of MLV liposomes}

The maximum amount of CI Disperse Violet 1 dispersed with the MLV liposomes was directly proportional to the phospholipid concentration in bilayers over the concentration range studied. From this correlation, the corresponding dye/phospholipid weight ratio $K$ was found to be 0.24 . The use of liposomes resulted in a large increase in dye dispersion efficiency compared with that of the conventional dispersing agent normally used for this dye [13].

\section{Stability of liposome suspensions}

The possible aggregation of liposomes during dyeing was monitored by measuring the variations in mean vesicle size using a quasi-elastic light scattering method [21]. The results obtained for liposome suspensions at the $K$ ratio of 0.24 and phospholipid concentrations ranging from 0.5 to $2.5 \mathrm{mmol} / \mathrm{l}$ are given in Table 1 . This shows a small increase in particle size during dyeing, the polydispersity indices remaining below 0.15 after treatment. This increase was slightly more noticeable at low phospholipid concentrations, where the mean vesicle size was maintained at around $400 \mathrm{~nm}$ and the polydispersity indices below 0.22 for more than $2 A \mathrm{~h}$.

\section{Dyeing kinetics}

Kinetic studies of dye exhaustion on untreated and chlorinated wool samples in the presence of MLV liposomes were carried out at different dye/phospholipid molar ratios. Figure 2 plots the exhaustion kinetics on untreated wool samples in the presence of liposomes at different phospholipid concentrations, with the dye concentration $(0.53 \mathrm{mmol} / \mathrm{l})$ remaining constant. Increasing the lipid concentration in the bilayers retarded the rate of dyeing, the maximum exhaustion (93\%) being reached at the lowest bilayer lipid concentration $(0.5$ mmol/l).

Figure 3 shows the dyeing kinetics of untreated wool samples in the presence of liposomes at dye concen-

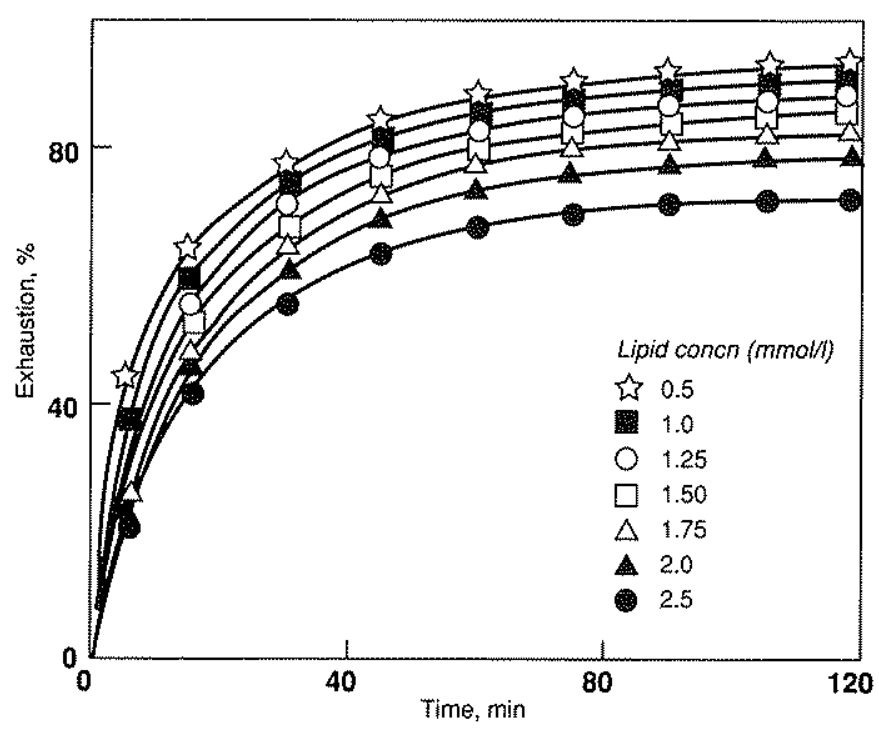

Figure 2 Plot of exhaustion rate of Cl Disperse Violet 1 on untreated wool in dyeing using liposomes at different lipid concentrations and constant dye concentration $(0.53 \mathrm{mmol} / \mathrm{h})$

Table 1 Mean particle size distribution of liposomes during dyeing ${ }^{a}$

\begin{tabular}{|c|c|c|c|c|c|c|c|c|c|c|}
\hline \multirow{3}{*}{$\begin{array}{l}\text { Time } \\
\text { (min) }\end{array}$} & \multicolumn{10}{|c|}{ Liposome properties at lipid conon in range $0.5-2.5 \mathrm{mmol} / \mathrm{l}$} \\
\hline & \multicolumn{5}{|c|}{ Mean vesicle size (nm) } & \multicolumn{5}{|c|}{ Polydispersity index } \\
\hline & 0.5 & 1.0 & 1.5 & 2.0 & 2.5 & 0.5 & 1.0 & 1.5 & 2.0 & 2.5 \\
\hline 0 & 402 & 402 & 401 & 399 & 399 & 0.090 & 0.087 & 0.085 & 0.085 & 0.085 \\
\hline 5 & 402 & 400 & 399 & 398 & 398 & 0.092 & 0.087 & 0.082 & 0.080 & 0.084 \\
\hline 10 & 400 & 399 & 399 & 396 & 395 & 0.094 & 0.088 & 0.086 & 0.084 & 0.086 \\
\hline 15 & 398 & 397 & 396 & 393 & 392 & 0.118 & 0.114 & 0.112 & 0.099 & 0.099 \\
\hline 30 & 404 & 398 & 397 & 394 & 392 & 0.120 & 0.118 & 0.117 & 0.102 & 0.102 \\
\hline 45 & 410 & 407 & 400 & 399 & 398 & 0.127 & 0.123 & 0.120 & 0.108 & 0.105 \\
\hline 60 & 419 & 417 & 415 & 409 & 401 & 0.132 & 0.127 & 0.123 & 0.118 & 0.112 \\
\hline 75 & 423 & 421 & 417 & 413 & 409 & 0.135 & 0.131 & 0.127 & 0.122 & 0.118 \\
\hline 90 & 427 & 425 & 421 & 417 & 412 & 0.140 & 0.136 & 0.129 & 0.124 & 0.122 \\
\hline 105 & 430 & 428 & 425 & 421 & 416 & 0.143 & 0.141 & 0.137 & 0.131 & 0.129 \\
\hline 120 & 432 & 430 & 427 & 422 & 418 & 0.147 & 0.143 & 0.140 & 0.135 & 0.134 \\
\hline
\end{tabular}




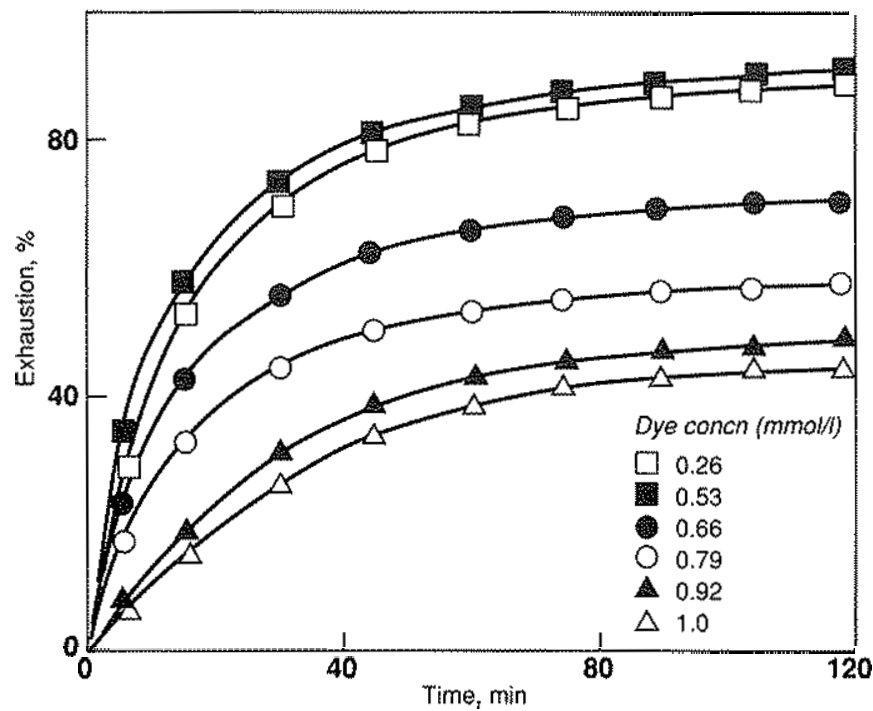

Figure 3 Plot of exhaustion rate of $\mathrm{Cl}$ Disperse Violet 1 on untreated wool at different dye concentrations and constant phospholipid concentration ( $1.0 \mathrm{mmol} / \mathrm{l})$

trations ranging from 0.26 to $1.0 \mathrm{mmol} / \mathrm{l}$, the phospholipid concentration remaining constant $(1.0 \mathrm{mmol} / \mathrm{l})$. A clear inhibition in dye exhaustion was also observed as the dye concentration in liposomes was increased. Thus the maximum exhaustion $(90.5 \%)$ was obtained at $0.53 \mathrm{mmol} / \mathrm{l}$ dye concentration (10 $\mathrm{mg}$ dye/g wool). Increasing the amount of dye in the liposomes resulted in a decreased dye exhaustion, the minimum being obtained for 1.0 $\mathrm{mmol} / \mathrm{l}$ dye ( $20 \mathrm{mg}$ dye/g wool).

Similar kinetic studies were carried out with MLV liposomes using chlorinated wool samples at different chlorination levels, the dye and phospholipid concentrations remaining constant $(0.53$ and $1.0 \mathrm{mmol} / \mathrm{l}$ respectively). For this purpose wool samples were treated with sodium hypochlorite solutions at different chlorine concentrations and $\mathrm{pH} 1.5$, as indicated above. The results obtained show that the rate of dyeing depended on the level of chlorination of the wool, and in turn the amount of cysteic acid present. Initially dye exhaustion increased more slowly than on untreated samples, although in the last stage of the dyeing this behaviour was reversed. From optical microscope observations of dyed samples, a regular dye distribution on untreated and chlorinated wool samples was observed in all cases, especially when using liposome suspensions at the dye/phospholipid molar ratio corresponding to the maximum dye exhaustion.

\section{Influence of liposomes on bonding of dyes on wool}

In order to find out whether liposomes as dye carriers caused changes to dye-fibre bonding forces after dyeing, dye was extracted from the samples using ethanol [7] and ammonia [13]; the results are given in Tables 2 and 3. In general ethanol extracted, in all cases, larger amounts of dye than did the ammonia solutions. This could be attributed to the high solubility of the dye in ethanol as
Table 2 Amounts of adsorbed, extracted and bonded dye after dyeing using liposome suspensions at different lipid concentrations $^{\mathrm{a}}$

\begin{tabular}{|c|c|c|c|c|}
\hline \multirow{2}{*}{$\begin{array}{l}\text { Lipid } \\
\text { concn } \\
(\mathrm{mmol} / \mathrm{l})\end{array}$} & \multirow{2}{*}{$\begin{array}{l}\text { Adsorbed dye } \\
\text { (mg dyef } \\
\text { g wool) }\end{array}$} & \multicolumn{2}{|c|}{ Extracted dye $e^{b}$} & \multirow{2}{*}{$\begin{array}{l}\text { Bonded dye } \\
\text { (mg dye/ } \\
\text { g wool) }\end{array}$} \\
\hline & & A & $\mathrm{B}$ & \\
\hline 0.5 & 9.300 & 1.45 & 0.012 & 7.838 \\
\hline 1.0 & 9.050 & 0.75 & 0.010 & 8.290 \\
\hline 1.25 & 8.810 & 0.70 & 0.010 & 8.100 \\
\hline 1.50 & 8.580 & 0.63 & 0.009 & 7.941 \\
\hline 1.75 & 8.250 & 0.58 & 0.009 & 7.661 \\
\hline 2.0 & 7.700 & 0.50 & 0.007 & 7.193 \\
\hline 2.5 & 7.200 & 0.43 & 0,005 & 6.765 \\
\hline
\end{tabular}

a Dye concn $0.53 \mathrm{mmol} / \mathrm{h}$, corresponding to $10 \mathrm{mg}$ dye $/ \mathrm{g}$ wool

b $A$ is $\mathrm{mg}$ dye/g wool fibre extracted by pure ethanol [7], B is $\mathrm{mg}$ dye/g wool fibre extracted by ammonia [13]

Table 3 Amounts of adsorbed, extracted and bonded dye after dyeing using liposomes at $1.0 \mathrm{mmol} / /$ phospholipid concentration and different dye concentrations

\begin{tabular}{|c|c|c|c|c|}
\hline \multirow{2}{*}{$\begin{array}{l}\text { Dye } \\
\text { conon } \\
\text { (mmol//) }\end{array}$} & \multirow{2}{*}{$\begin{array}{l}\text { Adsorbed dye } \\
\text { (mg dye/ } \\
\text { gwool) }\end{array}$} & \multicolumn{2}{|c|}{ Extracted dye } & \multirow{2}{*}{$\begin{array}{l}\text { Bonded dye } \\
\text { (mg dye/ } \\
\text { g wool) }\end{array}$} \\
\hline & & A & $\mathrm{B}$ & \\
\hline 0.26 & 4.320 & 0.60 & 0.010 & 3.710 \\
\hline 0.53 & 9.050 & 0.75 & 0.010 & 8.290 \\
\hline 0.66 & 8.803 & 1.02 & 0.013 & 7.770 \\
\hline 0.79 & 8.601 & 1.12 & 0.014 & 7.467 \\
\hline 0.92 & 8.403 & 1.28 & 0.013 & 7.110 \\
\hline 1.00 & 8.297 & 1.35 & 0.014 & 6.933 \\
\hline
\end{tabular}

a See Table 2

well as to the presence of dye superficially bonded to the fibres by non-polar forces. However, the fact that very small amounts of dye were extractable with ammonia could be attributed to the important contribution of the non-polar forces in the dye-fibre bonds. These interactions, especially those that are hydrophobic in nature, may play an important role in dye-fibre bonding inside the fibre.

Bearing in mind the data, it should be pointed out that, at constant dye concentration ( $0.53 \mathrm{mmol} / \mathrm{l})$, increasing the amount of lipids in liposomes resulted in decreased dye extraction with pure ethanol, whereas ammonia extractions showed very low values in all cases. However, increasing the amounts of dye in liposomes at a constant lipid concentration $(1.0 \mathrm{mmol} / \mathrm{l})$ yielded an increased extraction of dye with pure ethanol, the ammonia extraction values being also practically negligible in all cases (Table 3). With chlorinated wool fibres, ethanol extractions rose as the chlorine levels of treated samples increased. The ammonia dye extractions also showed negligible values (results not shown). 
Tables 2 and 3 also show the amount of bonded dye on wool fibres, given as a difference between the amounts of adsorbed dye and total dye extracted from untreated wool samples after treatments with these dye/liposome systems. The maximum amounts of bonded dye in the presence of liposomes were obtained at a phospholipid concentration $1.0 \mathrm{mmol} / \mathrm{l}$ and a dye concentration $10 \mathrm{mg}$ dye $/ \mathrm{g}$ wool $(0.53 \mathrm{mmol} / \mathrm{l})$. The weight ratio $K$ was, in this case, 0.25 , similar to the value at which these systems achieved the highest encapsulation efficiency (0.24).

The maximum amount of dye bonded to chlorinated wool samples was obtained at the lowest level of wool chlorination. However, samples treated at higher chlorine concentrations $(0.1-0.28 \%)$ showed similar amounts of bonded dye in all cases (results not shown).

\section{CONCLUSIONS}

A new method of wool dyeing using the anthraquinone disperse dye $\mathrm{CI}$ Disperse Violet 1 in the presence of multilamellar vesicle (MLV) liposomes has been investigated. It offers the potential to improve both the dye exhaustion and the dye-fibre bonding forces on wool.

The maximum encapsulation efficiency of MLV liposomes correspond to a dye/phospholipid weight ratio 0.24 , showing that the use of liposome suspensions can result in considerably improved dye dispersion efficiency compared with that of conventional dispersing agents [13]. MLV liposome suspensions at $\mathrm{pH} 5.5$ were stable during the dyeing process over the range of phospholipid concentrations studied.

The dye exhaustion on untreated wool fibres was directly dependent on the phospholipid concentration of bilayers and the total amount of dye dispersed by these systems. The maximum amounts of total bonded dye with liposomes were obtained at the same dye/ phospholipid concentrations at which liposomes reached the maximum dyeing exhaustion. This ratio also corresponded approximately to the weight ratio at which this system reached the maximum encapsulation efficiency.

The dyeing of chlorinated wool samples with liposomes resulted also in improved dye exhaustion, which depended also on the relative dye/lipid concentrations in the liposomes. Increasing the level of chlorination resulted in improved final dye exhaustion. However, the maximum amounts of bonded dye were obtained at the lowest levels of chlorination.

The use of liposomes enables the lipid concentration needed to form a dye dispersion to be dramatically reduced compared with more conventional methods. This method could also be investigated for potential use in the dyeing of wool/polyester to avoid wool damage at the high temperatures required by the conventional process. This will be the subject of future investigations.

This work was supported by funds from DGICYT (Dirección General de Investigacion Científica y Técnica) (programme PB91-0065), Spain. The authors acknowledge the expert technical assistance of $\mathrm{Mr} \mathrm{G}$ von Knorring.

\section{REFERENCES}

1. D Chapman, Liposome technology, Vol. 1, Ed. G Gregoriadis (Boca Raton Florida: CRC Press, 1986) 1.

2. M T Paternostre, M Roux and J L Rigaud, Biochem., 27 (1988) 2668.

3. B Almog et al., Biochem., 29 (1990) 4582 .

4. D Levy et al., Biochem., 29 (1990) 9480.

5. T Inoue, T Yamahata and R Shimozawa, ]. Colloid Interface Sci, $\mathbf{1 4 9}$ (1992) 345.

6. A de la Maza, J L Parra and I Sanchez Leal, Langmuir, 8(1992) 2422.

7. A de la Maza et al., J.S.D.C., 108 (1992) 540.

8. G Nelson, Rev. Prog. Coloration, 21 (1991) 72.

9. PR Brady, Rev. Prog. Coloration, 22 (1992) 58.

10. JWang and $\mathrm{H}$ Åsnes, J.S.D.C., 107 (1992) 314

11. E Barni et al. J. Disper. Sci. Technol., 9 (1988) 75.

12. A de la Maza, J L Parra and P Bosch, Text. Research J., 61 (1991) 357.

13. E R Trotman, Dyeing and chemical technology of textile fibres (High Wycombe, Bucks.: Charles Griffin, 1984) chapter 21.

14. WS Singleton et al., J. Amer. Oil Chem. Soc, 42 (1965) 53.

15. A D Bangham, M M Standish and J C Watkins, J. Mol. Biol, 13 (1965) 238.

16. F Szoka et al., Biochim. Biophys. Acta, 601 (1980) 559.

17. A Helenius and K Simons, Biochim. Biophys Acta, 415 (1975) 29.

18. D Lichtenberg, J Robson and E A Dennis, Biochim. Biophys. Acta, 737 (1983) 285 .

19. $\mathrm{M} C \mathrm{R}$ Rand, $\mathrm{A} E \mathrm{E}$ Greenberg and M I Taras, Standard methods for the examination of water and waste water, 466 (Amer. Public Health Assocn, Washington 1976).

20. Norma UNE 55-528-77 II, 'Iodometric method to determine the concentration of active chlorine in the sodium hypochlorite solutions'.

21. Standard specifications for test methods IWTO 23-70 (F), corresponding to the CTFLI, Paris 1969. 